\title{
Labor Pain: Perception of the Parturient and Midwife Evaluation
}

\author{
Catia Borges $^{1}$, Claudia José ${ }^{1}$, Patricia Sancho ${ }^{2}$, Maria Barros ${ }^{3}$, Margarida Sim-Sim ${ }^{3, ~ *}$ \\ ${ }^{1}$ Algarve Hospital Center, Faro, Portugal \\ ${ }^{2}$ Private Hospital of Algarve, Faro, Portugal \\ ${ }^{3}$ Nursing Department, University of Évora, Évora, Portugal
}

Email address:

catia.1.bgs@gmail.com (C. Borges),claudia_ponte@hotmail.com (C. José), ervilhitas@gmail.com (P. Sancho), mlb@uevora.pt (M. Barros), msimsim@uevora.pt (M. Sim-Sim)

${ }^{*}$ Corresponding author

\section{To cite this article:}

Catia Borges, Claudia José, Patricia Sancho, Maria Barros, Margarida Sim-Sim. Labor Pain: Perception of the Parturient and Midwife Evaluation. American Journal of Nursing Science. Vol. 6, No. 2, 2017, pp. 80-86. doi: 10.11648/j.ajns.20170602.12

Received: December 29, 2016; Accepted: January 12, 2017; Published: February 6, 2017

\begin{abstract}
Labor pain is an organic response which is important to make a correct assessment. Human evolution brought some modifications to the human body and as a consequence, labor pain is a major concern for women and simultaneously a professional matter for midwives. The aim of this study is to describe the perception of labor pain by the parturient and its evaluation by midwives of these episodes. A quantitative cross-sectional descriptive design was used. Non-parametric methods were applied because the sample obtained was not normal. The study was based on two convenience samples, totaling 164 parturients and 18 nurses. The visual analogue scale (VAS) was applied. Data were collected from 575 pain episodes. The age and parity of the parturient are not associated statistically with the intensity of labor pain at the time of hospital admission, as well as the presence of a companion. The level of pain mentioned by the parturients is significantly higher than indicated by the evaluation of the midwives. Midwives with between 6-10 and 11-15 years in practice assess pain at lower levels than nurses with 1-5 or 16-20 years in practice. Conclusions: The midwives underestimate labor pain. It is important to develop greater accuracy in assessing labor pain. Midwives can provide the stronger support if they do a correct evaluation of parturient's pain.
\end{abstract}

Keywords: Nursing, Midwife, Pain, Labor Pain

\section{Introduction}

Pain is a subjective and a multidimensional experience, it serves as alarm functions, protection, communication, help search. Labor pain is the most severe that human beings can support [1]. Paradoxically, accompanies moments of great happiness. Results from the physiological response based on the obstetrical dilemma. This dilemma resulting from bipedalism, led to the reduction of the anther-posterior diameter, the slope modification and configuration of the pelvis, nips and birth canal bends [2, 3]. Labor pain is a legacy of human evolution, to accommodate the vertical movement and the robust fetus before a pelvis that evolved from Australopithecus Afarensis to Homo Sapiens, adding uterine mechanical erasure-dilatation. It is explained in the species, the demand for help during the birth process [4]. In view of the approaching birth of warning signs or emergency pain, hospital demand can provide security. Arise as actors, the recipient/woman under parturition and caregiver/midwife. The level of pain of the parturient or her expectation is sensitive subject in the study results. Show some authors that the level of pain is labeled as much more painful than expected. In nulliparous women the expectation of pain prior to birth, is often underestimated [5] and the highest pain both observed in multiparous [6] and in nulliparous [7, 8]. Also despite the prenatal class frequency, recall the pain is referred to the extremes, both bearable as excruciating $[6,8]$.

The continued presence of the caregiver, is associated with lower consumption of analgesia, better use of resources [9, 10], reflecting the ancestry of human care at birth [2]. Although the personal characteristics of professionals to induce bias in the estimation of pain, one of its roles is to 
assess pain $[11,12]$. The health professional has an ethical and deontological duty of relieving the labor pain [13]. Need to conduct an individualized assessment and sensitive, given the subjectivity of pain. In Portugal, most parturient are assisted by midwives and its functions is part of the assessment of pain. Among the evaluation instruments to the Portuguese Midwives recognizes the Visual Analogue Scale (VAS) [14].

The hormonal activity of women in labor and post-partum, with elevated levels of endogenous oxytocin and increased prolactin, generates feelings of love and attachment in the sensitive period of maternity, brings with it a subsequent forgetting of the pain. However, the pain of labor is real, it is one of the main fears of parturient, and one of the main challenges of midwives assisting in a delivery. Although the memory of labor pain is typically lessened over time [8] and this leads to interest in knowing specifically the level of pain, the immediacy of the event.

\section{Aim of the Study}

The aim of the study is to describe the perception of pain of the parturient and evaluation of Midwives, both referred to the same episodes of labor pain. To accomplish this purpose, we registered the intensity of labor pain reported by parturient and their midwives.

\section{Subjects and Methods}

\subsection{Research Design}

This is a descriptive and cross-sectional study

\subsection{Research Setting}

The study is part of a post-graduate academic education in Master Midwifery at a Portuguese University. The data collection took place in the delivery room of a hospital in the south of Portugal.

\subsection{Subjects Parturient and Midwives}

For both groups, women giving birth and midwives, a convenience sample was used. Considering the academic context of the study, a limit of 90 days for data collection was established.

\subsubsection{Subjects - Parturients}

The sample of parturients was calculated as follows. In the referenced hospital, there were 1298 deliveries in the previous year, on average 108 by month. Estimated a total of 325 births in 90 days, through Krecje criterion and Morgan [15] it has calculated a sample of 165 women under labor. Invited 190 women as of consecutive admission to the hospital, obtained a convenience sample of 164 .

Inclusion criteria for parturients: a) Portuguese nationality; b) Term pregnancy with a single fetus in vertex presentation in labor active phase (i.e. greater cervicometry or equal to 3 $\mathrm{cm}$ and regular uterine contractions).

\subsubsection{Subjects - Midwives}

While there are 21 health care professionals in service, 18 agreed to participate in the study, representing $81.8 \%$ of the delivery room team. Four declined because of time constraints.

Inclusion criteria for Midwives: a) Portuguese nationality; b) At least one year of experience in maternal health.

\subsection{Tools of Data Collection}

\subsubsection{Instrumentation for the Parturient}

Considering the group of 164 parturient, the level of pain was measured by VAS presented in line with the ends of 0 (no pain) to 10 (worst pain imaginable) [14]. After each uterine contraction, it was asked to the woman in labor to mark on the intensity scale. It also recorded the last cervicometry since had occurred in the last minutes, considering the 5-minute time limit in order to be included in the data collection. The form used captured sociodemographic and obstetric data, and aspects of pre-natal preparation. This sociodemographic, obstetric and prenatal preparation data was collected within 24 hours following delivery, at a time chosen by the women giving birth.

\subsubsection{Instrumentation for the Midwives}

Considering the group of 18 midwives, pain assessment was carried out by VAS [14], always by the same midwife in every parturient, immediately after the self-assessment of the woman, but not knowing it. Midwives also answered a questionnaire containing sociodemographic aspects and time specialized exercise.

\subsection{Ethical Considerations}

The project was submitted in a hospital in the south of Portugal and approved by the relevant ethics committee, after passed at Master Midwifery Committee of University of Evora.

The data were collected after the informed consent form was signed by both the parturient and the midwife. Each subject was requested to sign the consent form before becoming a participant in the study.

\subsection{Data Analysis}

The parturients and midwives are described through descriptive statistics. Through data collection the following were obtained: a) Between two and five measures on the VAS for each parturient, b) a cervical measure of each parturient coinciding with the measure of pain, within five minutes from the moment the vaginal pain began, c) from two to five measures on the VAS by each midwife respecting the evaluation of pain felt and d) a global measure of pain that constitutes the mean of several episodes from the perspective of the midwives and the parturients.

Failing normal distribution (i.e. K-S $<0.05$ ), we opted for non-parametric tests. We used the Mann-Whitney test and also the Kruskal-Wallis test for respectively two or more than two independent samples. Wilcoxon test was used for paired samples and the Spearman test the correlations. It was assumed $p<0.05$ for critical value of significance. 
Data was analyzed using the Statistical Package for Social Sciences (SPSS) version 24.

The study has some limitations. The sample for the study included only one hospital. Convenience sample, not being able to generalize the results.

Despite the 577 episodes of pain assessment, the registry does not reach every episode accompanying the cervicometry of 3 to $10 \mathrm{~cm}$.

\section{Results}

\subsection{Sociodemographic Data of Parturient}

Parturients aged 13-44 years old $(\mathrm{M}=28.40, \mathrm{SD}=6.65)$.
The most representative class in educational attainment are the nine years of education $(\mathrm{n}=53 ; 32.3 \%)$, followed by secondary education $(\mathrm{n}=47 ; 28.7 \%)$, higher education $(\mathrm{n}=$ $43 ; 26.2 \%)$ and basic education $(n=21 ; 12.8 \%)$. Sixty-four parturients $(39.0 \%)$ were nulliparous, sixty-one $(37.2 \%)$ had a son and $39(23.8 \%)$ had two or more children.

\subsection{The Dynamics of Labor in Hospital Admission}

Most parturient entered the hospital with regular uterine contractions and cervicometry $3-5 \mathrm{~cm}(\mathrm{n}=141 ; 86 \%)$. The remaining $23(14 \%)$ dilation $6-8 \mathrm{~cm}$. Most admitted to 3 or 4 $\mathrm{cm}$ cervicometry was nulliparous (Figure 1).

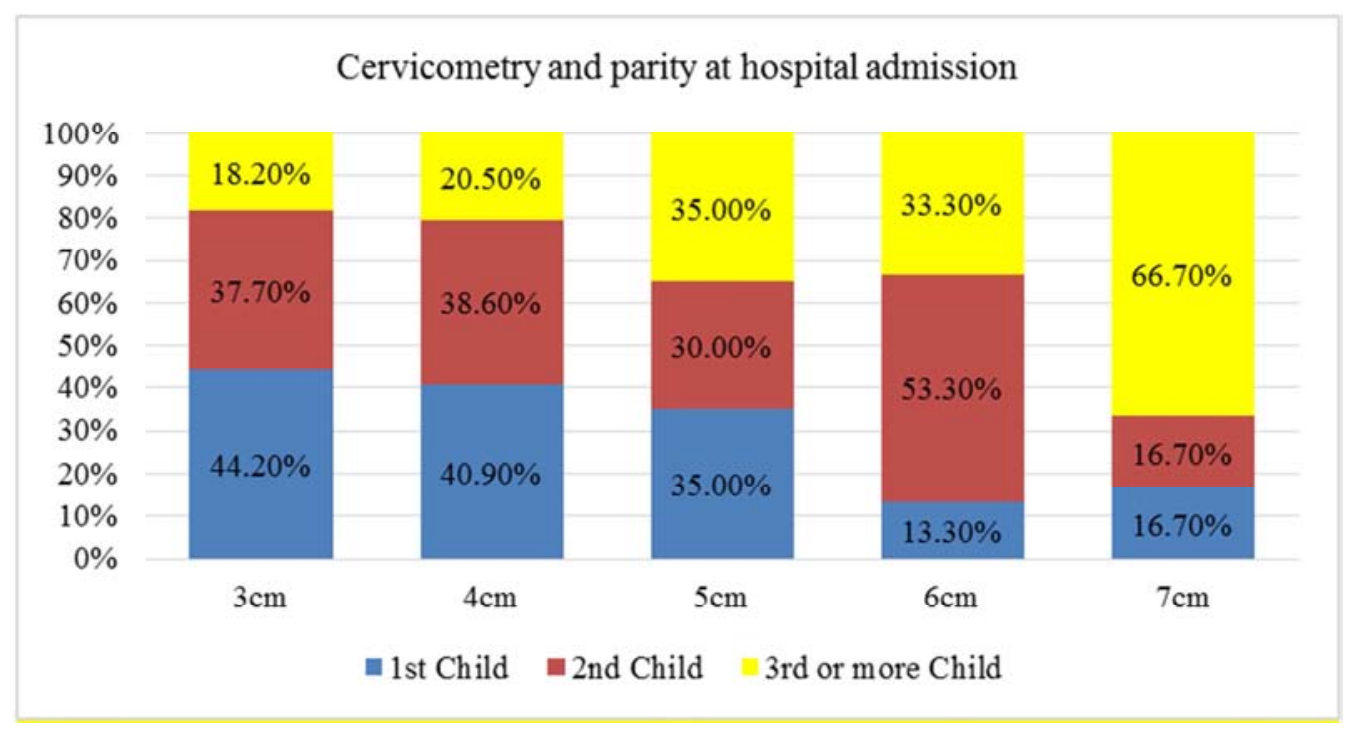

Figure 1. Representation of parturient according to the parity and the cervicometry at the time of hospital admission.

Most parturient did not attend prenatal class $(\mathrm{N}=113$; $68.9 \%$ ). On admission of the parturient, it was observed that the amplitude of cervicometry is independent of prenatal frequency class $(\mathrm{rs}=-0.003, \mathrm{p}=.967, \mathrm{n}=164)$.

\subsection{The Perception of Pain by Parturient Its Association with Sociodemographic and Obstetric Data}

At the time of admission, the perception of pain of the parturients ranged between 3 and $10(\mathrm{M}=7.03, \mathrm{SD}=1.838$; Med $=7.10)$. Considering the total of 575 evaluations episodes, the global average perception was $6: 38(\mathrm{SD}=1: 42$; Med $=6.85)$, ranging from 3.65 to 10 . The first record of perception of the woman in birth pain, the admission in the hospital, there was no association with age $(r=-0.009$, $p$ $=.905 ; \mathrm{n}=164)$. Also at the time of admission, by KruskalWallis test, no significant effect was found of both qualifications $(\mathrm{H}=5.392, \mathrm{p}=.249, \mathrm{df}=4)$ as the parity $\mathrm{H}=$ $0598 ; \mathrm{p}=.741 ; \mathrm{df}=2)$.

\subsection{The Perception of Pain by the Parturient and Its Association with the Presence of an Accompanying Figure}

During the labor there was present in most cases an accompanying $(\mathrm{N}=139 ; 84.8)$, the sexual partner the most representative ( $\mathrm{N}=114 ; 69.5 \%$ ), compared to figures such as the mother, sister or friend $(\mathrm{N}=27 ; 16.5 \%)$. Twenty-three mothers (14\%) where alone without chaperone. Using MannWhitney test showed that the perception of pain at enrollment is independent of the presence of chaperone ( $U=1649,500$; $=\mathrm{Z}-403, \mathrm{p}=.687$ ).

\subsection{Sociodemographic and Professional Career Data of the Midwives}

The midwives are an average age 41.07 years old $(\mathrm{SD}=$ 5.155) ranging from 29-52 years old. Exert as mean experts since there 8.29 years old $(\mathrm{SD}=5.89)$ ranging between 1 and 20 years. In his personal experience, most had experienced the pain phenomenon in the labor $(n=119 ; 72.6 \%)$.

\subsection{Pain Evaluation by the Midwives and Its Association with Time in the Profession}

Taking all the pain assessments conducted by midwives over labor reaches a mean of $4.75(\mathrm{SD}=1.76)$, with a range between .60 and 9.5. Age groups of nurses do not introduce differences in the overall assessment of pain $(\mathrm{p}=.114)$ as Figure 2 in box plot. 


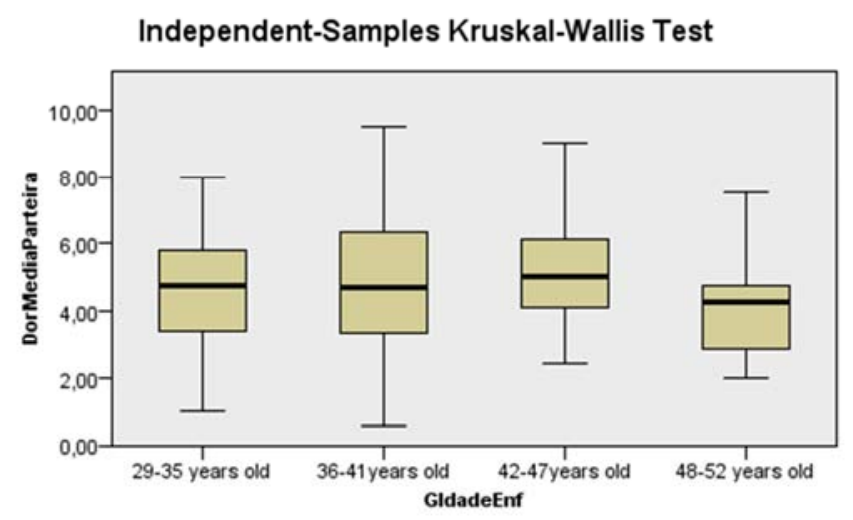

\begin{tabular}{|lr|}
\hline Total N & 164 \\
\hline Test Statistic & 5,961 \\
\hline Degrees of Freedom & 3 \\
\hline Asymptotic Sig. (2-sided test) &, 114 \\
\hline
\end{tabular}

\footnotetext{
1. The test statistic is adjusted for ties.

2. Multiple comparisons are not performed because the overall test does not show significant differences across samples.
}

Figure 2. Averages of the global assessment of pain by nurses as the age groups.

The midwives in middle phase of their career (i.e. 6-10 years and 11-15 years), assess the pain of the parturient with lower average $(\mathrm{M}=04.09, \mathrm{SD}=1: 41$ and $\mathrm{M}=3.40, \mathrm{SD}=$ 1.30 ) in respect of colleagues 1-5 years or to colleagues with 16-20 years. Through the Kruskal-Wallis test there are significant differences in overall pain level due to the sample $\left(\chi^{2} \mathrm{KW}(3)=18,972, \mathrm{p}=.000 ; \mathrm{n}=164\right)$. Multiple comparisons of Dunn orders demonstrate significant differences between the two central groups compared to the two extreme groups (Figure 3).

\section{Pairwise Comparisons of MidwiveTimeWorking}

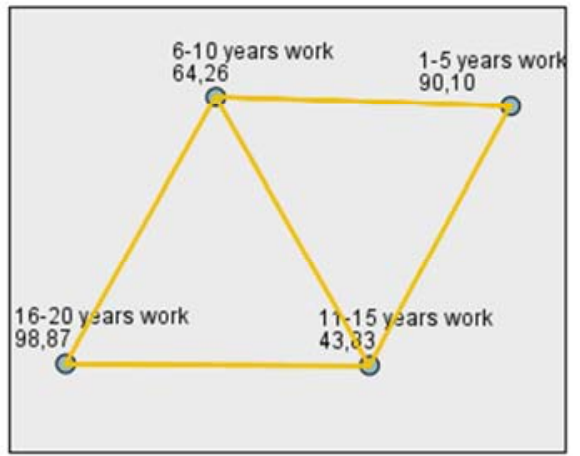

Each node shows the sample average rank of MidwiveTimeWorking.

\begin{tabular}{|c|c|c|c|c|c|}
\hline Sample1-Sample2 & $\begin{array}{l}\text { Test } \\
\text { Statistic }\end{array}$ & $\begin{array}{l}\text { Std. } \\
\text { Error }\end{array}$ & $\begin{array}{l}\text { Std. Test } \\
\text { Statistic }\end{array}$ & Sig. & Adj.Sig. \\
\hline $11-15$ years work $-6-10$ years work & 20,422 & 17,338 & 1,178 & 239 & 1,000 \\
\hline \multirow{2}{*}{$\begin{array}{l}11-15 \text { years work-15 years work } \\
15 \text { years work-6-20yeais }\end{array}$} & 46,264 & 16,787 & 2,756 & .006 &, 035 \\
\hline & $-55,035$ & 17,602 & $-3,127$ & .002 & 011 \\
\hline $6-10$ vears work-15 vears work & 25.842 & 9,023 & 2.864 & .004 & .025 \\
\hline $6-10$ vears work-16-20 vears work & $-34,613$ & 10,461 & $-3,309$ & .001 & .006 \\
\hline 15 years work- $16-20$ years work & -8.771 & 9.520 &. .921 & 357 & 1,000 \\
\hline
\end{tabular}

Figure 3. Multiple comparisons of the orders of Dunn to the overall assessment of the pain of the labor on the basis of their length of service as midwives. 


\subsection{Pain Evaluation by the Midwives Versus Parturients' Pain Perception}

There were performed between 2 to 5 episodes of pain assessment of each parturient during labor. It was applied with VAS 575 episodes of pain, collecting the perception of parturient and evaluation of respective midwife redounding records in 1150 , like figure 4 show from admission pain evaluation (Admission PE) till $5^{\text {th }}$ episode of pain evaluation $\left(5^{\text {th }} \mathrm{PE}\right)$.

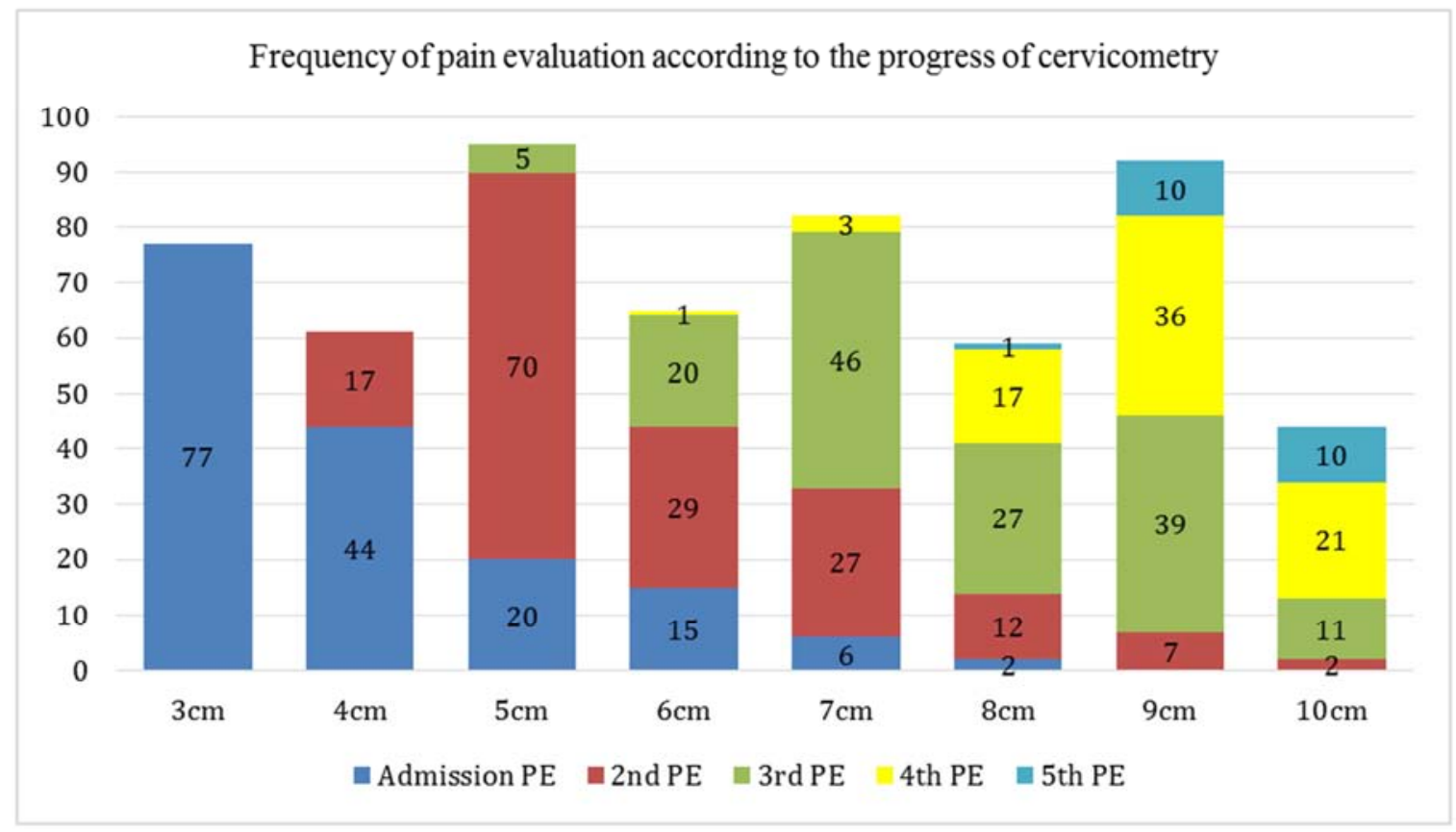

Figure 4. Pain evaluation frequencies according to the cervicometry.

Taking the overall perception of pain parturient versus the overall assessment by midwives, it was found using the Wilcoxon test for paired samples, the occurrence of significant differences $(Z=-11026, p=.000)$, with respect to the median the higher parturients $(\mathrm{Me}=6,854)$ compared to the midwives $(\mathrm{Me}=4,757)$ and a draw. In the same sense are all the episodes referred to cervicometry of $3-10 \mathrm{~cm}$. For example, in 77 episodes of pain to $3 \mathrm{~cm}$ dilated, the average of the scores given by the nurses $(\mathrm{Med}=3.90)$ was lower than the median corresponding assigned by parturients (Med $=7.200)$ with significant $(Z=-7,194 ; p=.000)$ and a draw. In other episodes' differences were in the same direction and always significant (Table 1).

Table 1. Wilcoxon test of medians of pain on lack of parturient and evaluation of midwives along the cervicometry.

\begin{tabular}{|c|c|c|c|c|c|c|}
\hline Cervicometry & Pain episodes & Median of VAS Parturient & Median of VAS Midwives & Evaluations & $\mathbf{Z}$ & $\mathbf{p}$ \\
\hline $3 \mathrm{~cm}$ & 77 & 7.200 & 3.900 & 1 & $-7,194$ & 0,000 \\
\hline $4 \mathrm{~cm}$ & 61 & 6.300 & 3.600 & 6 & $-6,475$ & 0,000 \\
\hline $5 \mathrm{~cm}$ & 95 & 6,800 & 3.700 & 4 & $-8,269$ & 0,000 \\
\hline $6 \mathrm{~cm}$ & 65 & 6.400 & 4.000 & 5 & $-6,705$ & 0,000 \\
\hline $7 \mathrm{~cm}$ & 82 & 7.000 & 4.700 & 2 & $-7,461$ & 0,000 \\
\hline $8 \mathrm{~cm}$ & 59 & 8.000 & 6.000 & 5 & $-6,400$ & 0,000 \\
\hline $9 \mathrm{~cm}$ & 92 & 8.600 & 6.650 & 8 & 7,727 & 0,000 \\
\hline Total & 575 & - & - & & - & - \\
\hline
\end{tabular}

\section{Discussion}

At admission, the majority of parturient, presenting regular contractions and cervical dilation of $3-5 \mathrm{~cm}$, was in the active phase of birth [16, 17]. Most came to the hospital with cervicometry $3 \mathrm{~cm}$, which can lead to long birth expectation. Going for hospital is a personal decision and the fear of not recognizing the onset of labor, not to be concrete what level of pain that leads to the decision, or the fear of not arrive on time or just stay in childbirth are applicants in pregnant women. The hospital seeks gives assistance safety. This reflects the ancestry of human care during birth, while justifying the presence of the figure caregiving $[2,18]$. Labor and delivery are not a solitaire event. Looking for support and assistance during labor is inherent to women in parturient condition.

Although nulliparous tend to refer greater pain, parity is not significantly associated with the intensity. The subject is controversial, because on the one hand actual results contribute to some studies [19], deny those who observe greater pain in nulliparous $[7,8]$ or otherwise in multiparous 
[6]. There are physical reasons for the nulliparous has more pain in the $1^{\text {st }}$ phase of the labor as dilation and fetal descent, for greater capacity of the uterine fibers takes place in early process. In multiparous, saves up high fetus during the $1^{\text {st }}$ phase of the labor and in these circumstances the fall in the $2^{\text {nd }}$ phase (i.e. pelvic phase) is more abrupt and rapid, intensely stimulates the nociceptors of the perineum and vulva making the perception of pain higher compared to nulliparous [8]. However, parity is not the major aspect in pain severity perception. For primparous, pain supporting level during labor is more relevant than for multiparous, but for both, higher severity, has association with physical environment, fear and anxiety [6]. Considering the role of midwives, those are examples of modifiable factors that can be changed to improve a better childbirth experience.

Although no significant differences, parturient who were accompanied reported lower levels of pain compared with those who had no escort. During the labor, the desire for proximity to someone familiar, is rooted in the history of human evolution [2] and highlights the emotional element of pain. Fear, anxiety, framed in a space with technicians who care but affectively are unknown, bring feelings of deep insecurity for women during childbirth [20], recognizing a strong association between pain and anxiety in laboring women [11]. As elementary as the relief of physical pain, will be the presence of someone who means the connection and belonging to what is familiar. It should be clear that the person is a significant need and desire for support during birth seems to be as old as humanity itself $[1,2,18]$. Reaffirm to this meaning of humanity, towards which is inherent to the physical nature of what is human and humanity to express compassion, recognizes who inhabit this physical nature.

In the current study, the frequency of prenatal classes is not related to the level of pain that they reached. These results are consistent with authors that refers to the gap between the expectations of pregnant woman against the pain and the lived experience of labor pain [20]. The scientific evidence, for reasons of quality of studies does not allow even realize a cause-effect relationship between the frequency of prenatal classes and the best/worst preparation for the woman to face the pain [21]. Prenatal classes in Portugal are not pure and there is no regular model, once a mix of currents are applied. This can be an important gap for midwives professional outcomes, once women can not value an educational program whose results don't relieve pain.

Compared to other studies [11], the midwife assess average pain episodes over labor, with lower values. On the other hand, they are less extreme professional and experienced that show the highest score. In fact professionals with long career assess labor pain at lower levels, but a larger number of controversy assisted birth is associated with high pain estimates [11]. The current results confirm studies that found in a wide range nurses that both appreciates depreciates excessively as pain [10]. Perhaps, in the current sample, the less expertise will lead to greater sensitivity and at the other end, the greatest proficiency will lead to increased compassion to pain.

Applying categorizing authors [17], the level of pain assessed by midwives was medium to moderate, given the perception of parturient with moderate levels and achieve severe pain. Thus, considering the underestimation or overestimation of pain when there is a difference of one unit between the two assessments $[10,22]$ it may be argued that in this sample the pain the laboring woman is overlooked. These results contribute to some authors that identifies underestimation of labor pain by health professionals [20]. In fact, the pain as subjective experience, it is a difficult phenomenon to measure. Labor pain causes conflicting feelings of anxiety, fear, excitement, joy, crying and others. In singular expression of human emotion, labor pain has become characteristic of the species. Facial and attitudinal expressive language of pain and compassion emerge from the other who witnesses the pain down to beneficiary caregiver approach, embodied in the birth care practices. Although in hands-off methodologies without tangible proceedings before the fetal expulsion, human emotional condition seems to need the support of figure achieved in the midwife. Thus the expression of species-specific pattern of human birth emerged the "obligate midwifery" [2].

During the labor is expected that nurses come into interaction with the women and prefer non-pharmacological methods of pain relief [1]. The assessment of labor pain is paramount in the midwives playing field and its role in the face of a woman in travail under the effect of pharmacological action of relief, is not in the true sense an independent action and not just part of the "normal birth" [18]. The midwife needs to conduct training in cognitivebehavioral therapy in order to have skills to support the mother to deal with labor pain, instead of fighting against pain [20]. For the professional practice of the midwife, it is important to develop a humanistic view of birth-related events. If from the beginning of the labor, midwives do not improve the relationship with the parturient, properly assessing pain, the species-specific essential relationship is not cultivated. Portugal has now good rates of mother and child mortality, improved after a more frequent delivery at hospital between the years 1960 and 1970. The technology had a relevant impact and the pharmacological pain relief grew enormously. Having a large availability of pharmacological methods, perhaps the midwives developed a faster method of pain relief, leaving for second plan other competencies for pain assistance and evaluation. But as we can see in a clinical setting, a new generation of women is beginning to emerge and that generation demands a more natural birth. Besides other reasons that can be summarized in a word like an humanized care culture, this is why midwives must continue to develop their expertise in pain evaluation.

\section{Conclusions}

Labor pain is species-specific and so it is necessary to know how it is experienced by the beneficiary and assessed 
by the caregiver. The study allowed the assessment of labor pain at the actual time of occurrence in immediate estimate of the episodes. This ensures greater accuracy in the score because it reduces the bias of memory. Parturient report high levels of pain compared to the assessment of midwives. The results suggest a wraparound care that poorly explores the knowledge of midwives. Valuing pain along the individually and sensitively pregnant women is important, as the relief and empowering their experience. At the same time are not negligible economic benefits to health care. The truth is that the alleviation of the parturient's pain is one of the most important skills that a midwife can possess.

\section{References}

[1] T. Klomp, A. de Jonge, E. K. Hutton, S. Hers, and A. L. Lagro-Janssen, "Perceptions of labour pain management of Dutch primary care midwives: a focus group study," (in eng), BMC Pregnancy Childbirth, vol. 16, p. 6, Jan 2016.

[2] K. R. Rosenberg and W. R. Trevathan, "Evolutionary obstetrics," (in eng), Evol Med Public Health, vol. 2014, no. 1, p. 148, 2014.

[3] L. T. Gruss and D. Schmitt, "The evolution of the human pelvis: changing adaptations to bipedalism, obstetrics and thermoregulation," (in eng), Philos Trans $R$ Soc Lond B Biol Sci, vol. 370, no. 1663, p. 20140063 , Mar 2015.

[4] R. Sreekanth and B. P. Thomas, "Human Evolution: The Real Cause for Birth Palsy," (in eng), West Indian Med J, vol. 64, no. 4, pp. 424-8, Sep 2015.

[5] R. Sanders and K. Lamb, "An exploration of the benefits and drawbacks of intrapartum pain management strategies," British Journal of Midwifery, vol. 22, no. 9, pp. 642-649, 2014.

[6] S. Hoshmandi, M. Dolatian, M. Kamalifard, and M. Ghoojazadeh, "Comparison of labor pain and factors affecting the pain perception among primiparous and multiparous women referring to women's private and state hospitals in Tabriz in 2010," Medical Journal of Tabriz University of Medical Sciences and Health Services, vol. 34, no. 3, p. 25, 2012.

[7] W. Christiaens, M. Verhaeghe, and P. Bracke, "Pain acceptance and personal control in pain relief in two maternity care models: a cross-national comparison of Belgium and the Netherlands," (in eng), BMC Health Serv Res, vol. 10, p. 268, 2010 .

[8] S. Labor and S. Maguire, "The Pain of Labour," Reviews in Pain, vol. 2, no. 2, pp. 15-19, 2008.

[9] M. J. Renfrew et al., "Midwifery and quality care: findings from a new evidence-informed framework for maternal and newborn care," (in eng), Lancet, vol. 384, no. 9948, pp. 112945 , Sep 2014.
[10] A. Baker, S. A. Ferguson, G. D. Roach, and D. Dawson, "Perceptions of labour pain by mothers and their attending midwives," (in eng), $J A d v$ Nurs, vol. 35, no. 2, pp. 171-9, Jul 2001.

[11] A. C. Williams, J. Morris, K. Stevens, S. Gessler, M. Cella, and J. Baxter, "What influences midwives in estimating labour pain?," (in eng), Eur J Pain, vol. 17, no. 1, pp. 86-93, Jan 2013.

[12] L. Mårtensson and I. Bergh, "Effect Of Treatment For Labor Pain: Verbal Reports Versus Visual Analogue Scale Scores - A Prospective Randomized Study," International Journal of Nursing and Midwifery, vol. 3, no. 4, pp. 43-47, 2011.

[13] OE and APEO, Documento de consenso "Pelo direito ao parto normal. Uma visão partilhada". Lisboa: Ordem dos Enfermeiros, 2012.

[14] OE, Dor. Guia orientador de Boa Prática. Lisboa: Ordem dos Enfermeiros, 2008

[15] L. Almeida and T. Freire, Metodologia da Investigação em Psicologia e Educação. Lisboa: Psiquilíbrios, 2007.

[16] J. L. Neal, N. K. Lowe, K. L. Ahijevych, T. E. Patrick, L. A. Cabbage, and E. J. Corwin, "Active labor" duration and dilation rates among low-risk, nulliparous women with spontaneous labor onset: a systematic review," (in eng), $J$ Midwifery Womens Health, vol. 55, no. 4, pp. 308-18, 2010 Jul-Aug 2010.

[17] J. H. Woo et al., "The degree of labor pain at the time of epidural analgesia in nulliparous women influences the obstetric outcome," (in eng), Korean J Anesthesiol, vol. 68, no. 3, pp. 249-53, Jun 2015.

[18] T. Boryri, N. M. Noori, A. Teimouri, and F. Yaghobinia, "The perception of primiparous mothers of comfortable resources in labor pain (a qualitative study)," (in eng), Iran J Nurs Midwifery Res, vol. 21, no. 3, pp. 239-46, 2016 May-Jun 2016.

[19] P. Manizheh and P. Leila, "Perceived environmental stressors and pain perception during labor among primiparous and multiparous women," (in eng), J Reprod Infertil, vol. 10, no. 3, pp. 217-23, Oct 2009.

[20] R. Talbot, "Self-efficacy: women's experiences of pain in labour," British Journal of Midwifery, vol. 20, no. 5, pp. 317$321,2012$.

[21] C. S. Brixval, S. F. Axelsen, S. G. Lauemøller, S. K. Andersen, P. Due, and V. Koushede, "The effect of antenatal education in small classes on obstetric and psycho-social outcomes - a systematic review," (in eng), Syst Rev, vol. 4, p. 20, 2015.

[22] E. Sheiner, E. K. Sheiner, R. Hershkovitz, M. Mazor, M. Katz, and I. Shoham-Vardi, "Overestimation and underestimation of labor pain," (in eng), Eur J Obstet Gynecol Reprod Biol, vol. 91, no. 1, pp. 37-40, Jul 2000. 